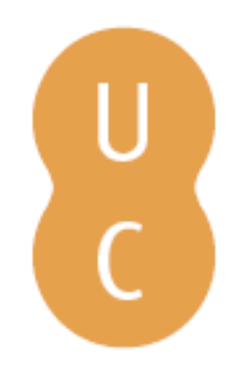

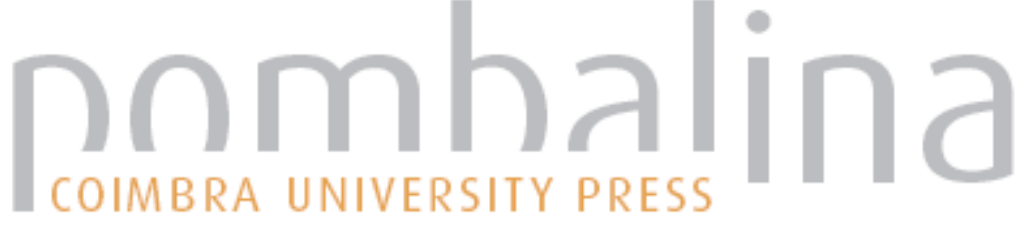

\section{Aspects from the history of quantum chemistry}

Autor(es): $\quad$ Gavroglu, Kostas; Simões, Ana

Publicado por: Imprensa da Universidade de Coimbra

URL

persistente: URI:http://hdl.handle.net/10316.2/31312

DOI: $\quad$ DOI:http://dx.doi.org/10.14195/978-989-26-0241-7_9

Accessed : $\quad$ 26-Apr-2023 07:11:07

A navegação consulta e descarregamento dos títulos inseridos nas Bibliotecas Digitais UC Digitalis, UC Pombalina e UC Impactum, pressupõem a aceitação plena e sem reservas dos Termos e Condições de Uso destas Bibliotecas Digitais, disponíveis em https://digitalis.uc.pt/pt-pt/termos.

Conforme exposto nos referidos Termos e Condições de Uso, o descarregamento de títulos de acesso restrito requer uma licença válida de autorização devendo o utilizador aceder ao(s) documento(s) a partir de um endereço de IP da instituição detentora da supramencionada licença.

Ao utilizador é apenas permitido o descarregamento para uso pessoal, pelo que o emprego do(s) título(s) descarregado(s) para outro fim, designadamente comercial, carece de autorização do respetivo autor ou editor da obra.

Na medida em que todas as obras da UC Digitalis se encontram protegidas pelo Código do Direito de Autor e Direitos Conexos e demais legislação aplicável, toda a cópia, parcial ou total, deste documento, nos casos em que é legalmente admitida, deverá conter ou fazer-se acompanhar por este aviso.

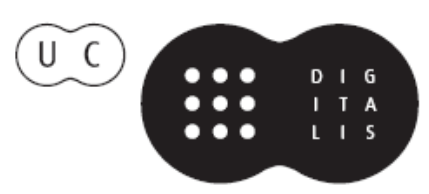




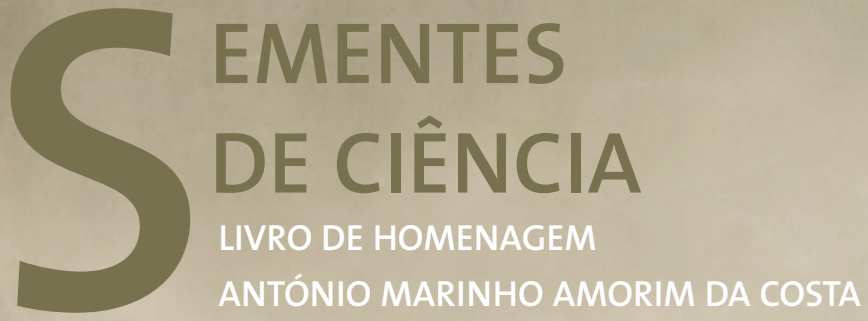

Sebastião J. Formosinho Hugh D. Burrows EDITORES 
Kostas Gavroglu

Department of History and Philosophy of Science - Athens University

kgavro@phs.uoa.gr

Ana Simões

Unit on the History and Philosophy of Science (SAHFC)

Center for the History of Science and Technology (CIUHCT- UL Group) University of Lisbon aisimoes@fc.ul.pt

IX.

\section{ASPECTS FROM THE HISTORY OF QUANTUM CHEMISTRY}

We have known António Amorim da Costa since the late 1990s, as we have been participating in the multinational project "The Evolution of Chemistry in Europe, 1789-1939" funded by the European Science Foundation (ESF). A physical chemist, Amorim da Costa became interested in the history of science in the late 1970s and has been contributing talks, papers and books, especially focusing on the history of chemistry in Portugal, addressed to lay and specialized audiences. ${ }^{1}$ His initial historical interest fell on the history of chemistry at the reformed University of Coimbra, its professors, ideas and practices, and their reactions to the chemistry of Lavoisier. He collaborated in the organization of the meeting on "Revolutions in Science" in Coimbra in 1986, and together with William Shea and the late Alan Debus, contributed to foster the discipline of the history of science in Portugal in the late $1980 \mathrm{~s}$ and early 1990s. ${ }^{2}$ For both of us who are actively involved in the further consolidation of the discipline in our respective countries, we know how difficult it should have been to take such initiatives and Antonio took. He, also, participated in the commemorative volumes celebrating the $200^{\text {th }}$ anniversary of the Academy of Sciences of Lisbon, again offering reflections on $18^{\text {th }}$ century chemistry in Portugal. ${ }^{3}$ His contributions to the history of science were extended to other periods, especially as a participant in the ambitious ESF project on the history of chemistry, in which he offered the international community his assessment of the role of chemistry in Portugal in late $19^{\text {th }}$ and early $20^{\text {th }}$ centuries. ${ }^{4}$ An active physical chemist who became a scientist-historian, Amorim da Costa has been also very supportive of the 
younger generation of professional historians of science in our respective countries, showing a rare gift for interacting with all of us. We are truly thankful to him.

Although we could have contributed to this volume with a discussion of the appropriation of the new sciences in the European periphery during the $18^{\text {th }}$ century, a topic to which we have both contributed and which is akin to the historical area which Amorim da Costa selected for his initial steps as a historian, we opted to offer our more recent reflections on the history of quantum chemistry, for two reasons. The first time the authors of this chapter both met with Amorim da Costa happened to be at the meeting of the ESF in Delphi, Greece, and following this meeting we contributed to the ESF project with a paper on textbooks in the history of quantum chemistry. ${ }^{5}$ Second, the history of quantum chemistry is probably a topic more appealing to many of those who will be reading this volume. ${ }^{6}$ We hope to present some of the new vistas the history of chemistry has to offer.

In 1969 in a symposium on the "Fifty Years of Valence" Charles Alfred Coulson, the writer of the well known textbook titled Valence, then Professor of Applied Mathematics at the University of Oxford, was emphatically declaring that one of the primary tasks of the chemists during the initial stage in the development of quantum chemistry was to escape from the thought forms of the physicists. ${ }^{7}$ Indeed. Among the many and, at times, insurmountable barriers during the becoming of quantum chemistry, perhaps the one hurdle that was the most incapacitating was the danger to develop a subdiscipline in chemistry that would be indistinguishable from a subdiscipline in physics. Hence, escaping the thought forms of the physicists was a strategic choice - not by all the protagonists, not even consciously pursued, but, surely, in the minds of those whose work eventually established quantum chemistry.

In 1927 Walter Heitler and Fritz London by using the then newly proposed Schrödinger equation, calculated the strength of the homopolar bond of the hydrogen molecule. They were able to show in no uncertain terms that the homopolar bond - a kind of mystery within the classical framework could be mathematically tackled and physically understood by using the 
recently formulated quantum mechanics, and, in fact, by using the even more mysterious exclusion principle. It came to be realised that everything depended on spin, a recently introduced purely quantum mechanical notion. In a short while, Friedrich Hund in Germany and Robert Sanderson Mulliken in the USA tried to develop a different framework. Especially Mulliken wanted to extend to molecules the Aufbau principle that Bohr had proposed for the atom. The molecular orbital approach became an amazingly successful schema, based in the understanding of band spectra and not involving the use of heavy mathematics. In the early 1930s, it was Linus Pauling who used quantum mechanics in his own peculiar way, developed the notion of resonance and with a forceful propaganda became the dominant figure of quantum chemistry, until more sophisticated mathematical methods and, especially, numerical techniques started developing after the second world war.

Right from the very beginning of this period, Paul Adrien Maurice Dirac, the most unphilosophical of the founders of quantum mechanics, had expressed what looked to many chemists like a modern curse upon their heads. ${ }^{8}$

The general theory of quantum mechanics is now almost complete, the imperfections that still remain being in connection with the exact fitting in of the theory with relativity ideas. These give rise to difficulties only when high-speed particles are involved, and are therefore of no importance in the consideration of atomic and molecular structure and ordinary chemical reactions, in which it is, indeed, usually sufficiently accurate if one neglects relativity variation of mass with velocity and assumes only Coulomb forces between the various electrons and atomic nuclei. The underlying physical laws necessary for the mathematical theory of a large part of physics and the whole of chemistry are thus completely known, and the difficulty is only that the exact application of these laws leads to equations much too complicated to be soluble. It therefore becomes desirable that approximate practical methods of applying quantum mechanics should be developed, which can lead to an explanation of the main features of complex atomic systems without too much computation. 
This then was the curse. In fact it was a double curse. The first was that chemistry was really physics, and, thus, chemists were delegated to the role of passive onlookers. The second curse was even more painful: it was indeed possible to solve the problems of chemistry but only on principle. Nothing could be done practically, no exact solutions were forthcoming.

What Dirac said is clear: after the advent of quantum mechanics, everything can be explained in terms of physics. No point in defending the autonomy of chemistry, no point in trying to devise new chemical theories. Everything in chemistry is a matter of calculations, it may be a pity that the equations are complicated, but if in due time new methods are devised, then all of "chemistry can be eaten with a spoon," as Heitler had recently remarked.?

But fortunately, the chemists chose to ignore Dirac's pronouncement. For more than a generation they devised theoretical schemata and approximation methods trying to overcome it. But what brought about triumph, was the electronic computer which, especially after the late 1950s, was behind the deep changes occurring in the practice of quantum chemistry. What was impossible to do analytically, and what was extremely cumbersome numerically, became one of the very first success stories of computers.

Yet the difficulties involved in the solution of the equations were immense, almost insurmountable. These difficulties were expressed in a dramatic manner by Douglas Hartree in a report for the Physical Society published in 1948. He underlined the significance of the newly developing calculating machines by writing: ${ }^{10}$

It has been said that the tabulation of a function of one variable requires a page, of two variables a volume, and of three variables a library; but the full specification of a single wave function of neutral $\mathrm{Fe}$ (the common iron) is a function of seventy-eight variables. It would be rather crude to restrict to ten the number of values of each variable at which to tabulate this function, but even so, full tabulation of it would require 1078 entries, and even if this number could be reduced somewhat from considerations of symmetry, there would still not be enough atoms in the whole solar system to provide the material for printing such a table. 
As it often happens, history has a way of getting around such catastrophic scenarios as that predicted by Dirac, and, much later, dramatically expressed by Hartree. Starting with the paper of Heitler and London, and continuing through the resonance theory of Pauling and the molecular orbitals of Hund and Mulliken, the history of quantum chemistry has been a history of a subdiscipline whose protagonists were trying to circumvent Dirac's pronouncements. What appeared as a liability for all those who wanted to apply quantum mechanics to chemical problems became an asset, since the impossibility to provide analytical solutions forced them to devise new concepts, to formulate new theoretical schemata and to develop new approximation methods. They did a great job, and the wealth of conceptual contributions, new theoretical insights into the behaviour of molecules and technical mathematical developments in methods of numerical solutions, gave rise to a new subdiscipline that some called theoretical chemistry and others quantum chemistry.

In this paper we suggest to narrate the development of an "in-between" discipline such as quantum chemistry through six interrelated clusters of issues which manifest the particularities of quantum chemistry along its evolving (re)articulations with chemistry, physics, mathematics and biology, as well as its institutional positioning. ${ }^{11}$

The first cluster involves issues related to the historical becoming of epistemic aspects of quantum chemistry: that is, the multiple contexts which prepared the ground for its appearance, the ever present dilemmas of the initial practitioners as to the "most" appropriate course to choose between the rigorous mathematical treatment, its dead ends, and the semi-empirical approaches with their many promises, the novel concepts introduced and the intricate processes of their legitimization. Quantum chemistry appears to have been formed through the confluence of a number of distinct trends, with each one of them claiming to have been the decisive factor in the formation of this discipline: neither the relatively straightforward quantum mechanical calculations of London and Heitler in 1927, nor the rules proposed by Mulliken to set an Aufbau principle for molecules, nor Pauling's reappropriation of structural chemistry within a quantum mechanical context, nor Coulson's and Hartree's systematic, but at times cumbersome, 
numerical approximations, could be said to have given quantum chemistry its epistemic content and institutional framework. The becoming of quantum chemistry has been the result of an attitude by many physicists, chemists, mathematicians, biologists and computer experts who did not feel constrained by any of these approaches so that to be discouraged from investigating the multitude of possibilities provided by the many alternatives. Though it may appear that there is a consensus that quantum chemistry had always been a "branch" of chemistry, this was not so during its history, and different scientific communities such as physicists and applied mathematicians attempted unsuccessfully to appropriate it differently.

The second cluster of issues is related to disciplinary emergence. The naming of chairs, university politics, textbooks, meetings, networking, as well as the alliances quantum chemists sought to establish with practitioners of other disciplines, became quite decisive in the formation of the character of quantum chemistry. The emergence of quantum chemistry in the institutional settings of Germany, the USA and the UK, and later on in France and Sweden, and a number of conferences and meetings of a programmatic character, helped to mould its character. A marginal activity at the beginning, it had the good luck to have gifted propagandists and able negotiators among its practitioners. Heitler's, London's and Hund's rather ascetic yet strong pleas for forcing chemical problems into the rigorous mathematical treatment behind the first principles of quantum mechanics; Mulliken's tirelessness in familiarizing physicists and chemists with the attractiveness of the molecular orbital approach; Pauling's aggressiveness to push resonance theory as the only way to do quantum chemistry; Coulson's incessant attempts to popularise his views in order to explain the character of valence; Daudel's and Pullmans' researches into molecules with biological interest; and Per Olov Löwdin's founding of a new journal, all these, contributed towards the gradual formation of the characteristics of the emerging subdiscipline.

The third cluster of issues is related with a rather unique development in the history of this subdiscipline: the re-articulation of the practices of the community after the early 1960s which was brought about by a single instrument - the electronic computer. The fundamental disadvantage of quantum chemistry, that is, the impossibility to perform analytical calculations, 
was, all of a sudden, turned into an invaluable advantage for the further legitimization of electronic computers. In the early days of computers it appeared that a whole subject depended on this particular instrument in order to produce trustworthy results. And, progressively, ever more scientists started to realise that "quantum chemistry is no longer simply a curiosity but is contributing to the mainstream of chemistry." ${ }^{2}$ The prospect of $a b$ initio calculations, which did not use experimental data built in the equations in any way, seemed to offer the promise of new and reliable results, and soon reached a sophistication and accuracy to serve the needs of each quantum chemist. The members of a whole disciplinary community, through a historically complicated process had attained a consensus about the coexistence of two approaches - the valence bond method and the molecular orbital approach. In a few years they became subservient to the limitless possibilities of computations provided by a particular instrument. By then, most of the leaders of the different traditions were nearing the end of their careers, since they had all gotten into quantum chemistry when they were very young. Fostered by the use of computers, applied to ab initio but also to semi-empirical calculations, members of the quantum chemical community recognized that a new culture of doing quantum chemistry was asserting itself and was carving a dominant place among the more traditional ones. It was identified by a novel style of scientific thinking, in which the increasing complexity of molecular problems was dealt with by means of mathematical modelling, and a burst of activities in relation to the writing and dissemination of computer programs. Eventually, it, even, became unnecessary to perform expensive experiments, since calculations would provide the required data!

The fourth cluster of issues is related to a hitherto totally neglected aspect of quantum chemistry, that is, its contingent character. Quantum chemistry could have developed differently, and it is straightforward to show that the particular form it took was historically situated, at times being the result of not only technical but also of cultural and philosophical considerations. The historiographic possibilities provided by the category of contingency for the development of the natural sciences have been intensely discussed among historians and philosophers of science. The elaboration 
of this issue is not in order to make partisan points, but in order to argue that, perhaps, "in-between" (sub)disciplines provide a privileged context in order to investigate the interpretative possibilities provided by the notion of contingency. Contingency is not an invitation to do hypothetical history. It is not an invitation to ruminate about meaningless "what if" situations, but rather to realise that at every juncture of its development, quantum chemistry had a number of ways along which it could have developed. What is important to understand is not what different forms quantum chemistry could or might have taken, but, rather, the different possibilities open for developments and the set of difficulties that at each particular historical juncture formed those barriers that dissuaded practitioners from pursuing these possibilities. Throughout this fifty year period, the criteria for assessing the "appropriateness" of the schema being developed gravitated between a rigorous commitment to quantum mechanics, a pledge towards the development of a theoretical framework where quasi-empirical outlooks played a rather decisive role in theory building, or a vow to develop approximate techniques for dealing with the equations. Such criteria were not, strictly speaking, solely of technical character, and the choices adopted by the various practitioners at different times, had been conditioned by the methodological, philosophical and ontological commitments as well as institutional considerations. It is only through such an analysis that we can understand the idiosyncratic culture of quantum chemistry.

The fifth cluster of issues is related to philosophy of science. It is undoubtedly the case that in recent years there has been an upsurge of scholarship in the philosophy of chemistry, and understandably quantum chemistry has played a prominent role in such a new situation. It is also the case that a number of papers and discussions have had as their starting point issues that have been all too common in the history of quantum chemistry. We have in mind issues such as reductionism, scientific realism, the role of theory, including its descriptive or predictive character, the role of pictorial representations and mathematics, the role of semi-empirical versus ab initio approaches, the status of theoretical entities and of empirical observations. ${ }^{13}$ The successes of quantum mechanics in chemistry induced many to bring to the fore a number of philosophical issues about chemistry, or to discuss 
problems other philosophers of science had been discussing, but, now, within the context of chemistry. Reductionism turned out to be one of the pivotal issues.

The sixth cluster is of a quasi-methodological and quasi-cultural character. The history of quantum chemistry displays instances which can be further understood in terms of "styles of reasoning". Such an approach can tell us how decisive the "style" of a researcher was for discovering new phenomena, developing effective methods or proposing novel explanatory schemata. ${ }^{14} \mathrm{~A}$ style of though brings into being candidates for truth. The types of styles are introduced as categories of possibilities, the range of possibilities depending upon that style.

The various developments in quantum chemistry help us to provide some answers to questions like: how can styles be differentiated from one another? Is the difference in styles merely an expression of personal idiosyncrasies? Is one justified to even talk about different styles of scientific inquiry when discussing the physical sciences, since the "objective" nature of what is being investigated seems to require a methodological uniformity? Is it at all meaningful to compare two different types of discourse? And, if it is, how are those differences to be expressed? A style possesses a peculiarly self-referential character about the criteria it sets, and against which it assesses its own coherence. What Heitler and London did by using group theory in the study of valence, what Mulliken proposed by extending Bohr's Aufbau principle to molecules, and proceeding into the articulation of molecular orbitals, and what Pauling did with his resonance theory, all these, can also be considered as alternative styles.

We suggest that these six axes - the epistemic content of quantum chemistry, the social issues involved in disciplinary emergence, the contingent character of its various developments, the dramatic changes brought about by the digital computers, the philosophical issues related to the work of almost all the protagonists, and the importance of styles of reasoning in assessing different approaches to quantum chemistry - form the narrative strands of the history of quantum chemistry. And we venture to further propose that they may be a useful way to deal with the becoming of other "in-between" subdisciplines. It is, however, certainly the case that they appear to be 
indispensable for understanding how quantum chemistry developed during its first 50 years.

In what follows we opt to address one such issue - the impact of computers - in its multifarious interactions with the other axes.

After the Second World War, quantum chemistry had already acquired all the characteristics of an autonomous subdiscipline. Its conceptual framework, its theoretical schemata, its textbooks, university chairs, journals, conferences had all been expressions of a thriving community which had come to terms with the incapacitating prospect of the subdiscipline: that it is impossible to have analytical solutions to the equations. But, in the late 1950s and early 1960s, as we have already referred, the development of the electronic computer changed the everyday practices of the quantum chemists in a dramatic manner.

Two conferences capture in a most interesting way the changes that computers would bring about: the Boulder Conference of 1959 and the Conference at Maryland in 1970. The former dealt with molecular quantum mechanics, and speakers talked about their subject within a totally new rationale when one compares it with that of other earlier conferences. It was the framework formed by the realization that powerful computing machines were making their presence felt in no uncertain terms, and that they were becoming an indispensable aspect of the future of quantum chemistry. If the Conference of 1959 was heralding a new period of quantum chemistry, the Conference held in Maryland in 1970 on Computational Support for Theoretical Chemistry mapped the future of quantum chemistry in terms of the possibilities provided by computers, not simply as machines which facilitated the calculational work of chemists, but as instruments which would act as probes of an amazing exactness, often substituting the need for experiments. If in the deliberations of the Conference of 1959 what was reflected was that computers were to become an indispensable tool for quantum chemists, the discussions of the 1970 Conference reflected a totally new social vista: the amazing development of hardware and software, and the pivotal role of quantum chemistry in the development of computer technology as well as its mounting importance within chemistry. 
Organized by the National Science Foundation, the steering committee of the 1959 Boulder Conference included Mulliken and John Slater as representatives of the first generation of quantum chemists and strong believers in the promises of heavy computations. It also included some already well-known names of the younger generation such as Robert G. Parr, and Rudolph Pariser, both of whom worked out the approximation which bore their names. ${ }^{15}$ The topics to be discussed in the various sessions covered old and new themes, illustrating the incursions of the field into big molecules, the test of new calculational methods and computer programs, at the same time it highlighted the move from structure to molecular dynamics and the consideration of forces other than the chemical bond in playing a role in quantum chemistry. ${ }^{16}$

What makes the Boulder Conference an event with a particular interest for historians of science, was that it marked, in no uncertain terms, the transition from the founding generation of quantum chemists to a generation whose success would be dependent on the way they would make use of the electronic computers. During the Conference the promising prospects of the electronic computers were discussed together with the dangers these prospects could bring to the character of quantum chemistry as it had been articulated since the Heitler-London 1927 paper. Everyone was convinced that improving the calculational techniques and electronic hardware brought forth many and new results. But not everyone agreed on the extent to which the new practices distorted accepted norms, thus reconfiguring quantum chemistry (almost) beyond recognition.

Perhaps Bernard Ransil - one of Mulliken's close young collaborators at his Laboratory of Molecular Structure and Spectra in Chicago - was the person who better captured the "climate" of the meeting. His introductory paragraph is quite illuminating. ${ }^{17}$

The coming of age of the digital computer and its impact on the field of molecular structure has recently been variously characterized as "disastrous to theoretical chemistry" and as "the means which will enable modern structural chemistry to become less of an art and more of a science." Insofar as the digital computer provides the means for critical 
calculations upon which theoretical concepts may be justified, tested, or based, the author is inclined toward the latter point of view; insofar as the use of a digital computer might blunt one's critical faculties and stunt the free play of his scientific imagination, reducing his research to little more than calculations for the sake of calculations, he agrees with the former estimate. Obviously a wide middle ground exists where the digital computer, intelligently used as a research instrument, can quickly provide the theoretical chemists with accurate results to an illuminating but complex critical calculation. Properly used, the numerical experiment can be as much of an aid and stimulus to the theoretical chemist as a well thought out and executed physical experiment.

As it is clear from this initial statement, Ransil quotes views without acknowledging the sources, so that we can surmise that these views were widely circulating and were, in fact, characteristic of the shop talk of the community. These views expressed the core of a wide spectrum of opinions, which were no doubt expressed in the soul searching discussions during the conference. Interestingly, he did not uncritically embrace all promises of a golden future. But he emphasized that a number of household words for the quantum chemist such as bond order, bond length, charge density, conjugation, hyperconjugation, and resonance would "benefit from a reevaluation based upon accurate a priori quantum mechanical calculations." 18

Coulson was, we think, the protagonist of the Conference, trying to balance the worries of a generation that had established quantum chemistry and the aspirations of the younger practitioners. Despite his own contributions and those of his research associates to the calculation of molecular integrals using ever more elaborate computer programs, Coulson was never oblivious of the major shortcomings of their indiscriminate use and abuse. At the end of the 1950s he started realizing that deep changes had occurred within the community of quantum chemists.

Coulson delivered the after-dinner speech, summing the main trends of the meeting and listing the problems he felt were to occupy the chemists in the years to come. ${ }^{19}$ But in this speech one senses a very worried Coulson, a Coulson who realized that there are now deep and perhaps irreconcilable 
divisions in the community of quantum chemists. These are divisions that he felt are absolutely detrimental to the discipline.

In discussing the major conclusions from the Conference he noted:20

There is one of these [conclusions] about which I feel very strongly, and because it is of such great importance for any future conferences on molecular structure, I make no apology for coming straight to it. It seems to me that the whole group of theoretical chemists is on the point of splitting into parts... almost alien to each other....The situation is indeed serious. For my own part, I am very far from laughing at it, and I want us to look at as openly and as dispassionately as possible. The questions that we are really asking concern the very nature of quantum chemistry, what relation it has to experiment, what function we expect it to fulfill, what kind of questions we would like it to answer. I believe we are divided in our own answers to these questions.

The splitting, he thought, in the community resulted from the antagonism of two extreme groups. The first group possessed great computational skills and advocated that there are a number of problems that a dispute can only settle by computation since experiments are too difficult. To many people this group of chemists appeared to be moving away from the conventional concepts of chemistry, such as bonds, orbitals and overlapping hybrids "as to carry the work itself out of the sphere of real quantum chemistry." ${ }^{21}$ On the other extreme were calculations with very rough approximations for biological molecules. These calculations give quite interesting results but the approximations put forward would be greatly upsetting to the people who used extensively computers.

"Where, in all this, does "real" quantum chemistry lie?" Coulson wondered. The possibilities offered by the electronic computers enabled one to distinguish two levels of activity, a distinction with which most of the exponents of computing at the Conference agreed. It appeared then that 20 electrons was a criterion for the upper limit to the size of a molecule for which accurate calculations were expected to become practicable. Coulson thought that there was a deep distinction between those chemists whose 
main interest laid in the 1-20 range, and consequently thought in terms of full electronic computation, and those who did not think in these terms. The two groups deserved distinct names Group I (the electronic computors or ab initio-ists as some would call them) and Group II (the non-electronic computors or a posterior-ists). ${ }^{22}$

I cannot help thinking that the gap between the two groups is so large that there is now little point in bringing them together. This is probably the last conference of the old kind. In future we should either have two distinct conferences or be prepared to plan parallel sessions for group I and II enthusiasts.

But he thought that it would be an oversimplification to think that the difference is only a difference having to do with the use of electronic computers. In their desire for complete accuracy, Group I appeared to be prepared to "abandon all conventional chemical concepts and simple pictorial quality in their results." Against this the exponents of Group II argued that chemistry is an experimental subject, whose results are built into a pattern around quite elementary concepts. He did not make any effort to conceal that his sympathies lay with the latter, and re-emphasized that the role of quantum chemistry is to understand these concepts, and to reveal the essential features in chemical behavior. Nevertheless, he was also aware that none of these concepts could be made rigorous.

Coulson felt that it would be a serious loss if members of Group I did not maintain a close link with experiment and with conventional thought forms of chemistry. He felt strongly that there was a danger that Group I people will forget that chemistry is associated with the real world. He ended in a pessimistic mood. ${ }^{23}$

It is not surprising that the orientations of these two groups of quantum chemists are so different that cross fertilization has now become much less frequent than in earlier days.... Many members of Group I do not realize what is happening to them; and members of both groups display an undesirable lack of sympathy for each other's work. 
A few years later, in a meeting in Paris, Alberte Pullman, senior researcher at the CNRS and one of the founders of quantum chemistry in France, exhorted quantum chemists to reintroduce chemistry into their calculations and denounced the tendency on the part of many theoretical chemists to forget that quantum chemistry remained nonetheless chemistry, despite the possibility of increased accuracy in calculational standards due to the use of computers. The obsession for getting better and better values of parameters, integrals, or other quantities, gave the impression that for some, quantum chemistry aimed solely at "the reproduction of known results by means of uncertain methods," contrary to the other sciences which aimed at "using known methods to search for unknown results." 24

Whether chemistry had been forgotten in the euphoria of the age of the computer is a debatable issue. What, however, is not debatable is that from the very beginning of the period when chemical problems were examined quantum mechanically, everyone involved in the subsequent developments tried to understand the character of what resulted from the encounter(s) of chemistry with quantum mechanics. Was quantum chemistry an application to or use of quantum mechanics in chemical problems? Did quantum chemistry embrace the totality of chemical problems formulated in the language of physics, and which could be dealt by a straightforward application of quantum mechanics with, of course, the ensuing conceptual readjustments? Or was it the case that chemical problems could be dealt with only through an intricate process of appropriation of quantum mechanics by the chemists' culture? Research papers, university lectures, textbooks, meetings, conferences, presidential addresses, inaugural lectures, even correspondence among chemists and physicists became privileged sites for the discussion of these questions. By attempting to provide answers to these seemingly pedantic, and often implicitly posed, questions, various individuals or groups of individuals attempted to legitimize outlooks and define the status of quantum chemistry. They attempted, that is, to achieve an agreement about the degree of relative autonomy of quantum chemistry with respect to both physics and chemistry and, hence, about the extent of its non-reducibility to physics. 
Perhaps it may be argued that the involvement of almost all those who did pioneering work in quantum chemistry in the various discussions and disputes - either in their published papers or in their correspondence or in their public lectures - had to do with legitimizing the epistemological status of various concepts in order to be able to articulate the characteristic discourse of quantum chemistry. Legitimizing a discipline, however, is not only related to the clarification of the content of the proposed concepts and the correctness of certain approaches. The process itself is a rigorously "social" process, involving rhetorical strategies, professional alliances, institutional affirmations, presence in key journals and conferences etc. ${ }^{25}$

Well into the 1970s, the period when it became clear that computers were bringing dramatic changes to quantum chemistry, E.B. Wilson, the co-author of Introduction to Quantum Mechanics with Applications to Chemistry with Pauling, ${ }^{26}$ wrote a paper examining the impact of quantum mechanics on chemistry. He posed the following questions: Is quantum mechanics correct? Is ordinary quantum mechanics good enough for chemistry? Why should we believe that quantum mechanics is in principle accurate, even for the lighter atoms? Can quantum-mechanical calculations replace experiments? Has quantum mechanics been important for chemistry? Can many-particle wave-functions be replaced by simpler quantities? Based on the ways in which computers were being used in quantum chemistry, and worried about the lack of new ideas during the last twenty years, Wilson speculated on the possibility that the "computer age will lead to the partial substitution of computing for thinking." But he hoped for "new and better schemes," and he still believed that qualitative considerations would continue to dominate the applications of quantum chemistry. This was, after all, because of the special methodology of chemistry: ${ }^{27}$

Chemistry has a method of making progress which is uniquely its own and which is not understood or appreciated by non-chemists. Our concepts are often ill-defined, our rules and principles full of exceptions, and our reasoning frequently perilously near being circular. Nevertheless, combining every theoretical argument available, however shaky, with experiments of 
many kinds, chemists have built up one of the great intellectual domains of mankind and have acquired great power over nature, for good or ill.

Wilson was encapsulating the development of quantum chemistry in an amazingly succinct, yet shocking, way. His words show no attempt to polish the narrative or to turn the protagonists into heroes. Nor is there any attempt to be humble. And the message was clear: the history was messy, the result unique. From the very beginning, among the chemists there was an ambivalent attitude towards any new proposal of "how to do quantum chemistry" or, rather, "what to do with quantum mechanics when doing quantum chemistry."

By 1970, members of the first generation of quantum chemists were in their sixties and seventies. Some had already passed away: Hans Hellman was executed in 1938, London and John E. Lennard-Jones both died in 1954, and Hartree died four years later, in 1958. Heitler, Erich Hückel, Hund, and John H. Van Vleck were not any more contributors to the discipline. Pauling had been estranged from the discipline he founded and planned to dominate. Already by wartime his attention was drifting away to problems which shaped molecular biology. In fact, still active were just Mulliken, who was awarded the Nobel Prize in 1966, Slater and Coulson. Their groups nurtured many of the members of the new generation of quantum chemists.

Circulation, networking, exchange programs, textbooks, international meetings and summer schools were constitutive elements of the training of this whole new generation of practitioners. And they started defining the agenda of the discipline: Raymond Daudel, Bernard and Albert Pullman, Masao Kotani and Löwdin, Parr, Pariser and John Pople, B.L. Crawford, Harrison Shull, J.R. Platt, C.C.J. Roothaan, Charles W. Scherr, Ransil, M.P. Barnett, Samuel Francis Boys, Enrico Clementi, Roy McWeeney, George Hall, Klaus Appel, Jean Pierre Calais, Jan Lindenberg, Anders Fröman, and many more. The concern for bigger molecules extended the field of application of quantum chemistry to inorganic chemistry and solid-state physics, as well as to biology, medicine and pharmacology. The change of scale, from very small molecules to big molecules and macromolecules introduced new 
constraints into the discussion. And this trend helped the emergence of Quantum Biochemistry, Quantum Biology (and to a lesser extent to Quantum Pharmacology) as well as to Computational Chemistry, Molecular Engineering and Materials Science and Engineering. In a sense, with quantum chemistry's forays in biology, medicine and pharmacy, the centuries' old relations of the discipline with the precursors to these specialties resurfaced again, in the context of a sustained relation with physics and mathematics. Even the emergence of Philosophy of Chemistry has been closely associated with Quantum Chemistry. ${ }^{28}$

The story of quantum chemistry has been a story with a happy ending. A happy ending of a tortuous journey. The beginning of which was marked by a self negating realization: that there could be no analytical solutions to almost all the problems of chemistry by using quantum mechanics, though in most of the cases the relevant equation(s) could be written down. But, the nightmare was punctuated by a dream of a dream world. A single instrument, the electronic computer, promised a boundless frontier of numerical solutions of arbitrary exactness. With it however, as it often happens in dream worlds, came another realization: as the first pioneers were experiencing this new frontier, the attractions provided by the very instrument of salvation led many astray. The genesis and development of quantum chemistry as an autonomous subdiscipline owed much to those scientists who were able to realize that "what had started as an extra bit of physics was going to become a central part of chemistry." It owed much to those that managed to escape successfully from the "thought forms of the physicist" 29 by implicitly or explicitly addressing issues such as the role of theory in chemistry, the methodological status of empirical observations and virtual experiments, helped to create a new space for chemists to go about practicing their discipline. The ability to "cross boundaries" between disciplines was perhaps the most striking and permanent characteristic of those who consistently contributed to the development of quantum chemistry. Moving at ease between physics, chemistry, mathematics, and later biology, became a prerequisite to be successful in borrowing techniques, appropriating concepts, devising new calculational methods and developing legitimizing strategies. With the era of computers and the development of computer science, quantum 
chemists were among the first scientists to explore the potentialities of the new instrument, and even to collaborate in its development. In this way, they also became participants in what many dubbed as the Second Instrumental Revolution in chemistry. ${ }^{30}$ The discussion over changing practices and their implications for the evolving identity of quantum chemistry shows how the history of quantum chemistry illustrates one of the trends which more forcefully characterized "in-between" disciplines emerging throughout the $20^{\text {th }}$ century - the exploration of frontiers and the crossing of disciplinary boundaries, reinforced by the mediation of many new instruments.

\section{References}

${ }^{1}$ A list of publications of Amorim da Costa can be found at http://www1.ci.uc.pt/qfm/coordenador.html.

${ }^{2}$ A.M. Amorim da Costa, "Chemical Practice and Theory in Portugal in the Eighteenth Century," in William R. Shea, ed., Revolutions in Science-Their Meaning and Relevance (USA: Science \& Hist. Publications, 1988), pp. 239-265.

${ }^{3}$ A.M. Amorim da Costa, "Domingos Vandelli ( 1730-1816 ) e a cerâmica portuguesa," in História e Desenvolvimento da Ciência em Portugal. Publicações II Centenário da Academia de Ciências de Lisboa (Lisboa, 1986), vol. I, pp.353-371; "Thomé Rodrigues Sobral ( 1759 - 1829 ) - A Química ao serviço da Comunidade," pp.373-401; "A Universidade de Coimbra na Vanguarda da Química do Oxigénio," pp. 403-416.

${ }^{4}$ A.M. Amorim da Costa, "Chemistry and the Scientific development of the Country - 19th Century in Portugal," in D. Knight \& H. Kragh, eds., The Making of Chemistry - The Social History of Chemistry in Europe 1789-1914 (Cambridge: Cambridge University Press, Cambridge, 1998), pp. 265-287; "The Mirror of the Portuguese Chemical Laboratories in the First Decades of the Twentieth Century" (European Science Foundation Project The Making of Chemistry), Centaurus 39 (1997), pp. 332-342.

${ }^{5}$ Kostas Gavroglu, Ana Simões, "One face or many? The role of textbooks in building the new discipline of quantum chemistry," in Anders Lundgren, Bernadette Bensaude-Vincent, eds., Communicating Chemistry. Textbooks and their Audiences, 1789-1939 (USA: Science History Publications, 2000), pp. 415-449.

${ }^{6}$ Kostas Gavroglu, Ana Simoes Neither Physics nor Chemistry: A History of Quantum Chemistry (MIT Press, 2010)

${ }^{7}$ C.A. Coulson, "Recent Developments in Valence Theory. Symposium Fifty Years of Valence," Pure and Applied Chemistry, 24 (1970), 257-287, on 259 and 287. Emphasis not in original.

${ }^{8}$ P.A.M. Dirac, "Quantum mechanics of many electrons," Proceedings of the Royal Society A 123 (1929), 714-33, on 714, emphasis ours.

${ }^{9}$ London Archives, Heitler to London, September(?) 1927.

${ }^{10}$ D.R. Hartree, "The calculation of atomic structures," Reports of Progress in Physics, 11 (1948), 113-143, on 113 .

${ }^{11}$ In this paper we introduce ideas which are developed more fully in our forthcoming book. Kostas Gavroglu, Ana Simões, Neither Physics nor Chemistry. A History of Quantum Chemistry (Cambridge: MIT Press, forthcoming 2010). 
${ }^{12}$ N/A "Computational Support for Theoretical Chemistry," National Academy of Sciences, National Research Council, 1971, p.1

${ }^{13}$ David Baird, E.R.Scerri and L.C. McIntyre, eds., Philosophy of Chemistry. Synthesis of a new discipline (Dordrecht: Kluwer Academic Publishers, 2006); J. van Brakel, Philosophy of Chemistry. Between the manifest and the scientific image (Leuven: Leuven University Press, 2000); J.E. Early, ed., Chemical Explanation: characteristics, development, autonomy, Annals of the New York Academy of Sciences, 988 (2003); Kostas Gavroglu, Kostas, "Philosophical issues in the history of chemistry," Synthese, 111 (1997), 283-304; Special Issue "Theoretical Chemistry in the making: appropriating concepts and legitimizing techniques", Studies in the History and Philosophy of Science, 31 B(4) (2000); Robin Findlay Hendry, "Mathematics, representation and molecular structure," in Ursula Klein, eds., Tools and Modes of Representation in the Laboratory Sciences (Dordrecht: Kluwer Academic Publishers, 2001), pp. 221-236; "Autonomy, explanation, and Theoretical Values. Physicists and chemists on molecular quantum mechanics," Annals of the New York Academy of Sciences 988 (2003), 44-58; "The physicists, the chemists and the pragmatics of explanation," Philosophy of Science, 71 (2004), 1048-1059; The Metaphysics of Chemistry, n/d, http://www.dur.ac.uk/r.f.hendry/; P. Janich, and N. Psarros, eds., The autonomy of chemistry (Würzburg: Königshausen \& Neumann, 1988); Hans Primas Chemistry, quantum mechanics and reduction (Berlin: Springer, 1983); "Can we reduce chemistry to physics?", in G. Radnisky, ed., Centripetal Forces in the Sciences (NY: Pergamon Press, vol.2, 1988), pp. 119-133; J.L. Ramsey, "Molecular shape, reduction, explanation and approximate concepts," Synthese 111 (1997), 231-251; Eric R. Scerri "Bibliography on philosophy of chemistry", Synthese, 111 (1997), 305-324; Eric R. Scerri and L.McIntyre, "The case for philosophy of chemistry", Synthese, 111 (1997), 213-232; H. Vermeeren, "Controversies and existence claims in chemistry: the theory of resonance," Synthese, 69 (1986), 273-290; A.I. Woody, "Putting quantum mechanics to work in chemistry: the power of diagrammatic representations," Philosophy of Science (Proceedings), 67 (2000), S612-S627; R.G. Wooley, "The quantum interpretation of molecular structure," in Löwdin, Per-Olov, J-L Calais and O Goscinski, eds., Quantum chemistry - a scientific melting pot, International Journal of Quantum Chemistry 12 Sup 1 (1978),pp.307-13

${ }^{14}$ Ian Hacking, "Styles of Scientific Reasoning," in John Rajchman, Cornel West, eds., Post-Analytic Philosophy (Columbia: Columbia University Press, 1985), pp.145-165.

${ }^{15}$ Rudolf Pariser and R.G. Parr "A semi-empirical theory of the electronic spectra and electronic structure of complex unsaturated molecules. I", Journal of Chemical Physics 21, (1953), 466-471; "A semi-empirical theory of the electronic spectra and electronic structure of complex unsaturated molecules. II", Journal of Chemical Physics 21, (1953), 767-776; Robert G. Parr, "On the genesis of a theory," International Journal of Quantum Chemistry, 37 (1990), 327-347.

${ }^{16}$ R.G. Parr, "Introductory Note," Conference on Molecular Quantum Mechanics, University of Colorado at Boulder, June 21-27, 1960, Reviews of Modern Physics, 32 (1960), 169. Sessions dealt with atoms and small molecules, the many-body problem, density matrices, methods to deal with atoms in molecules, complex molecules, nature of the chemical bond, problems in structure and spectra, spectroscopy methods, reaction rates, and intermolecular forces.

${ }^{17}$ Bernard J.Ransil, "Studies in molecular structure. I. Scope and summary of the Diatomic Molecule Program," Reviews of Modern Physics, 32 (1960), 239-244, on 239.

${ }^{18}$ Ibid.

19 C.A. Coulson, "Present State of Molecular Structure Calculations," Conference on Molecular Quantum Mechanics, University of Colorado at Boulder, June 21-27, 1960, Reviews of Modern Physics, 32 (1960), 170-177.

${ }^{20}$ Ibid., on 172 .

${ }^{21}$ Ibid.

${ }^{22}$ Ibid., on 173.

${ }^{23}$ Ibid., on 174.

${ }^{24}$ Albert Pullman, "Propos d'Introduction. 1970: Bilan et Perspectives," Colloque International sur les Aspects de la Chimie Quantique Contemporaine, 8-13 July 1970, Menton, France, organized by R. 
Daudel et Alberte Pullman (Paris: Éditions du Centre Nationale de la Recherche Scientifique, 1971), pp. 9-16, on 13 and 16.

25 This is very clear, for instance, when one contrasts the impact of both Erich Hückel and Hans Hellmann in popularizing their ideas among chemists vis-à-vis the efforts by, let us say, Pauling.

${ }^{26}$ Linus Pauling, and E.B. Wilson, Introduction to Quantum Mechanics with Applications to Chemistry (New York: McGraw-Hill, 1935).

${ }^{27}$ E. B. Wilson, "Fifty Years of Quantum Chemistry," Pure and Applied Chemistry 47 (1976), 41-47, on 47.

${ }^{28}$ Note that in the 1977 symposium "Quantum chemistry melting point" there was a section especially devoted to philosophical issues in the quantum sciences and R.G. Wooley is one of the participants. Hans Primas, and J. Del Re are also instances of quantum chemists turned philosophers of science, and Erich Scerri was invited to participate in the volumes Fundamental world of quantum chemistry. A tribute to the memory of P-O Lowdin. And many other chemists, including the Nobel Prize winner Roald Hoffman and Pierre Lazlo, have been active players in the emergence and development of philosophy of chemistry. So there is clearly a strong interaction between the two disciplines.

${ }^{29}$ Coulson, "Recent Developments in Valence Theory," op.cit. (1), 259.

${ }^{30}$ See Carsten Reinhardt, Shifting and Rearranging: Physical Methods and the Transformation of Modern Chemistry (Sagamore Beach, Mass.: Science History Publications, 2006). 